\title{
Microgram per Square Meter per Hour
}

National Cancer Institute

\section{Source}

National Cancer Institute. Microgram per Square Meter per Hour. NCI Thesaurus. Code C73727.

A dose calculation unit expressed in microgram(s) per square meter per period of time equal to sixty minutes. 